\title{
An Investigation on Substance Misuse Treatment, Mental Health Care Providers' Perception on Relapse: A Cross Sectional Study
}

\author{
Charles Blessings Maloya' ${ }^{1}, 0$ mero Gonekani Mwale ${ }^{2^{*}}$ \\ ${ }^{1}$ St John of God Community Services, Po Box 744 Mzuzu, Malawi \\ ${ }^{2}$ The Catholic University of Malawi, Department of Community and Mental Health, P. o. Box 5452, \\ Limbe, Malawi
}

Received: May 8, 2017; Accepted: June 9, 2017; Published: June 21, 2017

*Corresponding author: Omero Gonekani Mwale, The Catholic University of Malawi, Department of Community and Mental Health, P. o. Box 5452, Limbe, Malawi. E mail: omeromwale@gmail.com

\begin{abstract}
Introduction: Relapse is a common treatment outcome for many substance misusers. How a relapse is perceived may decree how it can be responded to. This study aimed at investigating substance misuse treatment, mental health care providers' perception of relapse.
\end{abstract}

Methods: This study employed a cross sectional research design. The sample was drawn from two drug and alcohol treatment services in Glasgow City, Scotland. Data was collected using self-administered questionnaires which were analyzed by using SPSS.

Results: The results indicated that $n=25(92 \%)$ reported having a better understanding of their role legitimacy when caring for clients with relapses. Only $n=4(15 \%)$ reported that there is little that can be done to help clients who have relapsed. Not surprisingly, $n=1(4 \%)$ was a participant who was uncertain of his counselling skills and believed that clients with several relapses cannot be treated.

Conclusion: In conclusion, there was inconsistency between providers' knowledge and their reaction to relapse. Therefore, emotional reactions if left unchecked may constitute a barrier to provision of care and may negatively impact treatment outcomes.

Keywords: Prevention Of Relapse, Substance Misuse Treatment, Mental Health Care

\section{Abbreviations}

AAPPQ- Alcohol and Alcohol Problems Perception Questionnaire; AVE- Abstinence Violation Effect; DDPPQ- Drug and Drug Problems Perception Questionnaire; GDCC- Glasgow Drug Crisis Centre; PLS - Plain Language Statement

\section{Background}

Substance misuse has for many years been recognized as a chronic condition characterized by high rates of relapse $[31,7,35,25]$. A relapse may be rated as one of the core features of drug and alcohol addiction and probably the most difficult clinical problem in the substance misuse treatment services $[36,13,6]$.
Many clients often return to their previous state of alcohol or drug use within few months after treatment despite advances in the provision of relapse prevention interventions $[33,16,4]$.

Research indicates that occurrences of relapse in individuals with substance misuse problems is high, regardless of the substance used, be it alcohol, heroin or cocaine and does not differ from other chronic medical diseases, such as, diabetes, asthma or hypertension [18,15,17,14,24]. Generally, it has been consistently reported that about $40 \%$ to $90 \%$ of clients with substance misuse problems relapse following treatment $[5,15,19]$. These figures may highlight the significance of relapse in the substance misuse treatment services.

The ideal response of the service provider, therefore, when relapse has occurred could be examining and understanding the circumstances that have led to the relapse; working with the client in order to support him or her to change [30]. However, whilst a relapse could be a positive consequence that is likely to prepare the substance misuser to prevent future relapses, the evidence largely from the general practice suggests that sometimes service providers become emotional and feel that this client group wastes their time and expensive hospital resources $[26,23,32,29,11]$. Eventually, the care rendered is likely to be compromised [34].

It has also been reported in many literatures that relapse is one of the significant challenges that substance misuse treatment services encounter $[36,9]$. The evidence suggests that many people with substance misuse problems often return to their problematic substance use soon after treatment $[34,4,16]$. This client group may increase the demand on care services as well as service providers' case workloads. Baker \& Intagliata's study found out that increased workload was more likely to 
influence service providers to have a reactive approach to clients [3]. Furthermore, Meldrum \& Yellowlees argue that service providers are likely to experience additional emotional strain if their caseloads are increased by clients who have relapsed. Eventually, their willingness to provide treatment diminishes [22].

Due to the very nature of substance misuse problems, clients with relapses are likely to be common in many treatment services and are likely to increase the demand for care services. The available evidence suggests that some service providers perceive this client group negatively [32].

Therefore, this current study aimed at investigating how substance misuse treatment providers perceive relapse and the implications of their perception of the care rendered to relapsed individuals.

Specifically, this study was guided by the following research question. (1) What are the substance misuse treatment providers' perceptions of relapse?

\section{Methods}

\section{Study design and context}

The study used a cross sectional research design. The sites for this research study were Phoenix Futures Services and Glasgow Drug Crisis Centre located within Glasgow City in the United Kingdom. These sites were purposefully chosen because the sites were specialized substance misuse treatment services and they were viewed as the best sites for eliciting the perception of relapse from the service providers who have experience and expertise in the management of the relapse.

\section{Participants}

The population for this study was all substance misuse treatment providers at Phoenix Futures Services and Glasgow Drug Crisis Centre (GDCC).

\section{Sampling}

A non-probability convenience sampling method was used to identify participants for the study. The convenient sampling method builds upon the selections of the subjects that suits the convenience of the researcher or are 'first to hand' [8]. This sampling method was chosen because it was predicted that the study may experience difficulties to have many volunteers to fill questionnaires and to be interviewed. However, the convenient sampling method 'run counter to the rigour of scientific research' and a much more systematic and predefined approach was required [8]. Since the required sample was small and the study did not permit statistical generalization, Ritchie \&Lewis counter argue that in this case it may matter less as to how subjects are chosen [28]. Therefore, every member of staff who was easily accessible by expressing his or her interest to take part in the research was included. A total of 27 staff members (12 from GDCC and 15 from Phoenix Futures) volunteered to participate in the research study. All the 27 participants filled up the questionnaire and 9 participants ( 4 from GDCC and 5 from Phoenix Futures) out of the 27 participants were also interviewed.

\section{Instrumentation and Data collection}

\section{Instrumentation}

The self-completion questionnaire was adopted to collect data. The researcher identified and rephrased a validated Drugs and Drug User's Problems Perceptions Questionnaire in order to specifically pick perception of relapse rather than drug user's problems in general [34]. For example, the phrases 'drug problems' and 'drug users' in the original questionnaire were rephrased to 'relapse' and 'substance users with a relapse' respectively. The rating scales were maintained. The revised questionnaire was pretested to two students who took part in the pretesting of the interview guide. Necessary amendments were also done after discussions with the participants, such as, adding question number 23 and 25 (See additional file). The revised questionnaire was then named Relapse Perception Questionnaire.

\section{Data collection}

Service providers who volunteered to participate in the research study were given questionnaires to complete. A Plain Language Statement (PLS) and a consent form were attached to the questionnaire. Participants were advised to read the plain language statement and get their questions answered before completing questionnaires. They were further advised to sign a consent form if they were still interested to continue participating in the research. However, at Glasgow Drug Crisis Centre it was difficult to meet staff members to advertise the study for volunteers. Instead, an electronic copy of the PLS, consent form and the questionnaire were sent to the service manager who forwarded them to service providers' email addresses. Some printed copies with returning envelop and postage stamps were also left for some service providers opting for hard copies.

\section{Data analysis}

The questionnaire data was entered into the Statistical Package for the Social Science (SPSS) for easy analysis of responses into frequencies and percentages. (Table 2)

\section{Ethical considerations}

Permissions to access the study subjects were sought from both sites after the study proposal was approved by the University of Glasgow Ethics Committee. After the permissions to access the study subjects were granted, meetings to advertise the research study to members of staff were arranged and conducted.

Participation in research was entirely voluntary; hence, it was imperative that participants were well informed about what it was that they were volunteering for. Therefore, 
details about the research were included in the plain language statement which was given to participants to read and get their questions answered before they decided to participate in the research study. An informed consent form was developed for participants to endorse their signatures as evidence that they had understood the intention of the research study. The consent form also reassured the study participants that their rights would be promoted during data collection, analysis and in the study report.

\section{Results}

The total sample consisted of $(\mathrm{N}=27)$ service providers; 19 females (70\%) and 8 males (30\%). Their age ranges were: 20 30 years (22\%); $31-40$ years (37\%) and $41-50$ years ( $41 \%)$. The majority of the participants $(41 \%)$ had worked at the study site for 1 - 5 years while $22 \%$ and $18 \%$ of the participants had worked for 6-10 years and 11-20 years respectively. Three participants $(11 \%)$ had worked at the study site for less than a year and the rest (8\%) had worked for more than 21 years.

The majority of the participants (89\%) belonged to 'others' profession. They identified themselves as the voluntary sector, addiction/drug workers, therapy workers, support workers and day service workers. Addiction/drug workers were the majority (33.3\%) in the 'others' profession category (Table 1).

\begin{tabular}{|c|c|c|c|}
\hline & Profession & Frequency & Percentage \\
\hline \multicolumn{4}{|c|}{ Age ranges } \\
\hline & 20-30 years & 6 & 22 \\
\hline & $31-40$ years & 10 & 37 \\
\hline & $41-50$ years & 11 & 41 \\
\hline & Total & 27 & $100 \%$ \\
\hline & Nursing & 1 & $3.7 \%$ \\
\hline & Social work & 2 & $7.4 \%$ \\
\hline \multirow{6}{*}{ Others } & Addiction/drug workers & 9 & $33.3 \%$ \\
\hline & Therapeutic workers & 4 & $14.8 \%$ \\
\hline & Support workers & 3 & $11.1 \%$ \\
\hline & Voluntary workers/sector & 5 & $18.6 \%$ \\
\hline & Day service workers & 3 & $11.1 \%$ \\
\hline & TOTAL & 27 & $100 \%$ \\
\hline
\end{tabular}

\section{Likert scale perception questions responses}

Participants were also assessed on their role when caring for a relapsed client. The results in (Table 2) below shows that, on average, about $92 \%$ of the participants $(n=25)$ reported having a better understanding of their role legitimacy when caring for clients with relapses. Only 4 participants (14.85\%) reported that there is little that can be done to help clients who have relapsed. Not surprisingly, two were the participants who were uncertain of their counselling skills and believed that clients with several relapses cannot be treated. (Table 2)

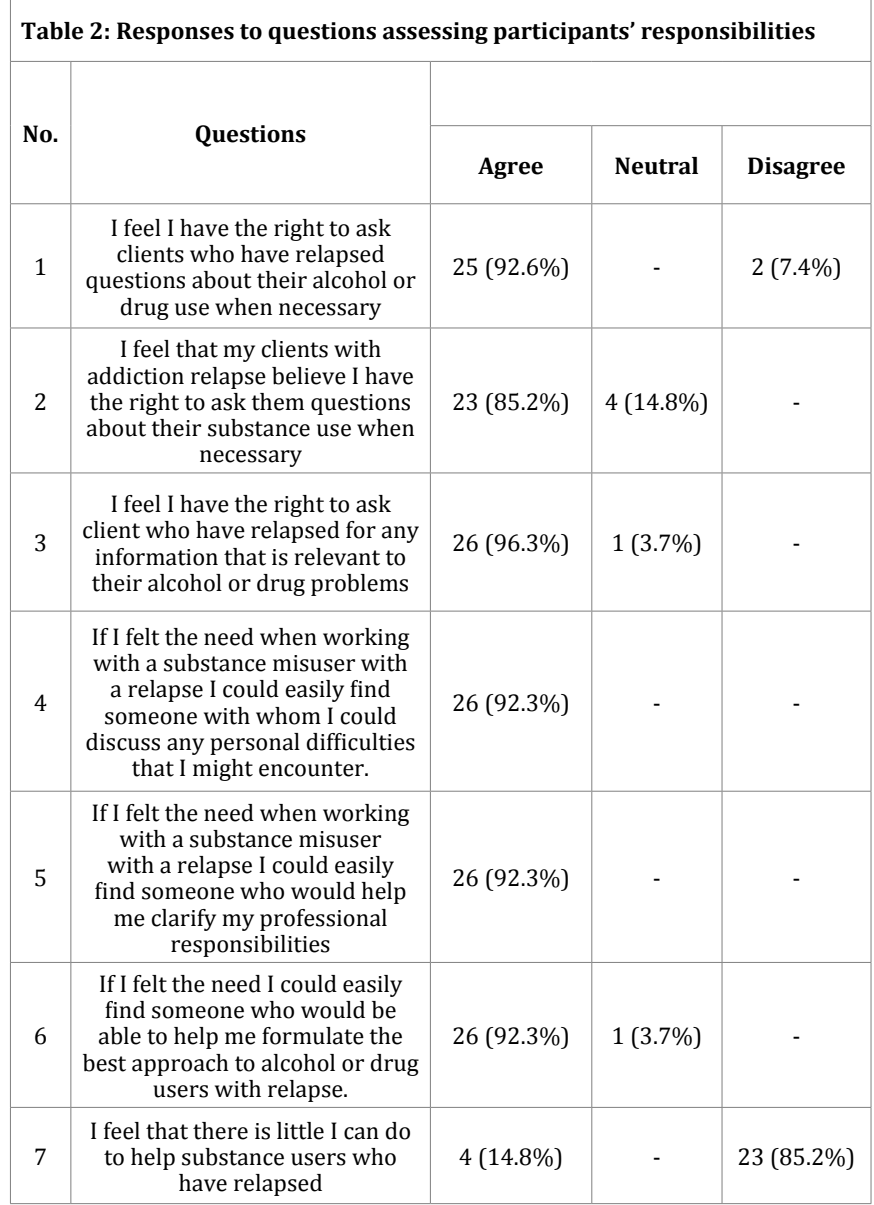

\section{Discussion}

The study found that the majority of the substance misuse treatment providers who participated in this study had a positive perception towards relapse and had a caring attitude towards clients with relapses. Relapse was perceived as part of the recovery cycle. This finding corroborates the ideas of Prochaska, et al. who suggested that people who have a desire to change pass through the stages of change (pre-contemplation, contemplation, preparation, action and maintenance stage) in more cyclical and circuitous pattern [27]. The relapse forms part of the change cycle as many people fall back several times to the earlier stages before or after reaching the maintenance stage. The 
understanding of relapse by the service providers would appear to indicate the knowledge that the participants had about relapse within the context of the change model [27]. This finding may not be surprising as the study subjects were drawn from specialized alcohol and drug treatment services where management of relapse forms the major part of their work. In addition, the findings would appear to suggest that service providers had received training whether formal or informal (on-job training) that might have influenced their positive perception of relapse.

It appears that there are some similarities between the feelings of annoyance expressed by the participants in this present study and those described in the study of McLaughlin, et al. where the service providers were emotional about the clients. This finding offers some cause for concern and a further study with more focus on service providers' feelings towards relapse is suggested since the emotional reaction may have implications on care provision and treatment outcomes [23].

The study results further showed that relapse was viewed as an event that offer opportunities for clients and service providers' learning. Two thirds of the participants suggested that relapse may provide an occasion for reflection and learning about the flaws in the previous plan and may give clues on how to develop the next plan to avoid the pitfalls of the failed attempt. These results are consistent with those of other studies, who suggested that a relapse could be a failure that prepares the service provider and the client for later success as more information may be acquired before or during the relapse which may be used to prevent relapses in the future [35,2]. The result in the present study may be explained by the fact that the majority of the participants had a good number of years working with substance misuse clients and some participants had personal experiences on how relapse assisted them to recover from substance addiction.

\section{Limitations}

A number of important limitations need to be considered. First, the study used a convenience sample due to time limitation. This method has been described as to 'run counter to the rigour of scientific research' [8]. A much more systematic and predefined approach was required in order to claim the findings as a better representation of how service providers in the study sites perceive relapse. However, the study has provided an insight into the issue under investigation for a possible bigger study.

Secondly, the sample size was relatively small and was limited only to two sites. This resulted in the generation of information from few informants. With a small sample size, caution must be applied, as the findings might not be generalised to a larger population.

\section{Recommendations}

The evidence from this study suggests that perception of relapse among the service providers was generally positive. However, there is inconsistency between the providers' knowl- edge and their reaction to relapse. This finding has important implications for workforce development considering that relapse is the huge part of substance misuse problems [15].

The negative attitudes from the few substance misuse treatment providers need to be addressed to enhance the provision of quality care. The evidence suggests that therapeutic attitudes to working with substance abusers can be improved through training $[20,1]$. On the contrary, other studies did not report improved therapeutic attitudes following training [10]. Therefore, training alone may not be enough to change negative attitudes. The service providers' work satisfaction needs to be addressed as well.

\section{Conclusion}

The study acknowledges that due to the methodological weakness for the selection of the study participants and the small sample size, these results cannot be generalized. Nevertheless, the study findings have gone some way towards enhancing the understanding of how service providers in the specialist substance misuse treatment services perceive relapse.

Emotional reactions if left unchecked may constitute a barrier to the provision of care and may negatively impact on treatment outcomes [12].

\section{Authors Contribution}

CBM, designed the study, developed the protocol, organized and collected data, analyzed and interpreted the results. MOG, drafted the manuscript, reviewed and edited the manuscript.

MOG, drafted the manuscript, revised and edited the study protocol and critically revised the manuscript. Both authors read and approved the final manuscript.

\section{Funding}

The authors would like to thank St John of God Hospitaller Services-Malawi for the financial support.

\section{References}

1. Abed RT, Neira-MunozE. A survey of general practitioners' opinion and attitude to drug addicts and addiction. Br J Addict. 1990;85(1):131136.

2. Allen J, Lowman C, Miller WR. Perspectives on precipitants of relapse. Addiction. 1996;91 Suppl:S1-244.

3. Baker F, Intagliata J. Case management in Liberman R (Ed) handbook of psychiatric rehabilitation. New York: Macmillan. 1992.

4. Brown SA, Tapert SF, Tate SR, Abrantes A. The role of alcohol in adolescent relapse and outcome. J Psychoactive Drugs. 2000;32(1):107-115. doi: 10.1080/02791072.2000.10400216

5. Brownell KD, Marlatt GA, Lichtenstein E, Wilson GT. Understanding and preventing relapse. Am Psychol. 1986;41(7):765-782.

6. Chung T, Maisto SA. Relapse to alcohol and other drug use in treated adolescents: review and reconsideration of relapse as a change point in clinical cours. Clin Psychol Rev. 2006;26(2):149-161. doi: 10.1016/j. 
cpr.2005.11.004

7. Connors GJ, Maisto SA, Zywiak WH. Understanding relapse in the broader context of post-treatment functioning. Addiction. 1996;91 Suppl:S173-89.

8. Denscombe M. The good research guide for small-scale social research projects (3rd ed). England: McGraw Hill Open University Press. 2007.

9. DiClemente CC. Addiction and change: how addictions develop and addicted people recover. New Yolk: The Guilford Press. 2006.

10. Ford R, Bammer G, Becker N. The determinants of nurses' therapeutic attitude to patients who use illicit drugs and implications for workforce development. J Clin Nurs. 2008;17(18):2452-2462. doi: 10.1111/j.1365-2702.2007.02266

11. Galvani S, Hughes N. Working with alcohol and drug use: Exploring the knowledge and attitudes of social work students. Br J Soc Work. 2010;40(3):946-962. doi: 10.1093/bjsw/bcn137

12. Gilchrist G, Moskalewicz J, Slezakova S, Okruhlica L, Torrens M, Vajd R, et al. Staff regard towards working with substance users: a European multi-centre study. Addiction. 2011;106(6):1114-1125. doi: 10.1111/ j.1360-0443.2011.03407

13. Gordon SM, Sterling R, Siatkowski C, Raively K, Weinstein S, Hill PC. Inpatient desire to drink as a predictor of relapse to alcohol use following treatment. Am J Addict. 2006;15(3):242-245. doi: 10.1080/10550490600626556

14. Gossop M, Marsden J, Stewart D, Kidd T. The National Treatment Outcome Research Study (NTORS): 4-5 year follow-up results Addiction. 2003;98(3):291-303.

15. Gossop M, Marsden J, Stewart D, Rolfe A. Patterns of drinking and drinking outcomes among drug misusers. 1-year follow-up results. J Subst Abuse Treat. 2000;19(1):45-50.

16. Gossop M, Stewart D, Browne N, Marsden J. Factors associated with abstinence, lapse or relapse to heroin use after residential treatment: protective effect of coping responses. Addiction. 2002;97(10):12591267.

17. Greenwood GL, Woods WJ, Guydish J, Bein E. Relapse outcomes in a randomized trial of residential and day drug abuse treatment. J Subst Abuse Treat. 2001;20(1):15-23.

18. Hubbard RL, Craddock SG, Flynn PM, Anderson J, Etheridge RM. Overview of 1-year follow-up outcomes in the drug abuse treatment outcomes study (DATOS). Psychology of addictive behaviors. 1997;11(4):261-278. doi: 10.1037/0893-164X.11.4.261

19. Krampe H, Stawicki S, Wagner T, Bartels C, Aust C, Ruther E, et al. Follow-up of 180 alcoholic clients for up to 7 years after outpatient treatment: impact of alcohol deterrents on outcome. Alcoholism, clinical and experimental research. 2006;30(1):86-95. doi:10.1111 /j.1530-0277.2006.00013

20. Lindberg M, Vergara C, Wild-Wesley R, Gruman C. Physicians-in-training attitudes toward caring for and working with patients with alcohol and drug abuse diagnoses. South Med J. 2006;99(1):28-35.
21. Marlatt GA. Taxonomy of high-risk situations for alcohol relapse: evolution and development of a cognitive-behavioral model. Addiction. 1996;91 Suppl:S37-49.

22. Meldrum L, Yellowlees P. The measurement of a case manager's workload burden. Aust N Z J Psychiatry. 2000;34(4):658-663.

23. McLaughlin DF, McKenna H, Leslie JC. The perceptions and aspirations illicit drug users hold toward health care staff and the care they receive. J Psychiatr Ment Health Nurs. 2000;7(5):435-441.

24. McLellan AT, Lewis DC, O’Brien CP, Kleber HD. Drug dependence, a chronic medical illness: implications for treatment, insurance, and outcomes evaluation. JAMA. 2000;284(13):1689-1695.

25. McKay JR, Franklin TR, Patapis N, Lynch KG. Conceptual, methodological, and analytical issues in the study of relapse. Clin Psychol Rev. 2006;26(2):109-127. doi: 10.1016/j.cpr.2005.11.002

26. Polivy J, Herman CP. If at first you don't succeed. False hopes of selfchange. Am Psychol. 2002;57(9):677-689.

27. Prochaska J0, DiClemente CC, Norcross JC. In search of how people change. Applications to addictive behaviors. Am Psychol. 1992;47(9):1102-1114.

28. Ritche J, Lewis J. Qualitative research practice: a guide for social science students and researchers. London: SAGE Publications. 2003.

29. Roche AM, Guray C, Saunders JB. General practitioners experiences of clients with drug and alcohol problems. British journal of addiction. 1991;86(2):263-275.

30. Seneviratne H, Saunders B. An investigation of alcohol dependents' attributes for their own and 'others' relapses. Addiction research. 2000;8(5):439-453.

31.Shiffman S. Conceptual issues in the study of relapse. In M. Gossop (Ed.). Relapse and addictive behavior (pp. 149-179). London, Tavistock/Routledge. 1989.

32. Siegfried N, Ferguson J, Cleary M, Walter G, Rey JM. Experience, knowledge and attitudes of mental health staff regarding clients' problematic drug and alcohol use. Australian and New Zealand journal of Psychiatry. 1999;33(2):267-273. doi: 10.1046/j.1440-1614.1999.00547

33. Walton MA, Castro FG, Barrington EH. The role of attributions in abstinence, lapse, and relapse following substance abuse treatment. Addict Behav. 1994;19(3):319-331.

34. Watson H, Maclaren W, Kerr S. Staff attitudes towards working with drug users: development of the Drug Problems Perceptions Questionnaire. Addiction. 2007;102(2):206-215. doi: 10.1111/j.13600443.2006 .01686

35. White WL, Boyle M, Loveland D. Alcoholism/Addiction as a chronic disease: from rhetoric to clinical reality. Alcoholism treatment quarterly. 2002;20 (3-4):107-129.

36. Witkiewitz K, Marlatt GA. Relapse prevention for alcohol and drug problems: that was Zen, this is Tao. Am Psychol. 2004;59(4):224-235. doi: 10.1037/0003-066X.59.4.224 